\title{
PENGARUH METODE TUTOR SEBAYA BERBASIS VIDEO YOUTUBE TERHADAP SIKAP KEMANDIRIAN BELAJAR MAHASISWA PGSD UNISRI
}

\author{
Jumanto $^{1)}$, Ema Butsi Prihatsari ${ }^{2)}$ \\ Program Studi Pendidikan Guru Sekolah Dasar \\ Universitas Slamet Riyadi Surakarta \\ ${ }^{1}$ antokarof@gmail.com; ${ }^{2}$ butsinegara@gmail.com
}

\begin{abstract}
The aims of this research was to determine: (1) difference of attitude of self-reliance learning of PGSD UNISRI students between before and after using peer tutor based on Youtube videos method and (2) effectiveness of using peer tutor based Youtube videos method toward independence attitude of PGSD student of UNISRI. The data of this research are primary data, obtained from questionnaire and documentation. This research is an experimental research. This research used One Group Pretes Posttes Design. Population in the study were all students of PGSD UNISRI Academic year 2016/2017. Sampling technique used in this research is purposive sampling. Instrument validity is tested by means of Construct Validity. Data were analyzed by $t$-test and $N$ gain test. $T$ test results obtained sig (2-tailed) of 0,000 whose value is less than 0.05. This means rejecting $H_{o}$ and it can be concluded that there is a significant difference in the attitude of learning independence before and after using peer tutor based Youtube videos methods. Result of calculation with $\mathrm{N}$-gain that is equal to 0,734 which means effectiveness of using peer tutor based Youtube videos method in improving attitude of independence learn at high criterion.
\end{abstract}

Keywords: Peer Tutor, Video, Attitudes of Learning Independence

\section{PENDAHULUAN}

Kualitas pembelajaran yang baik dapat diupayakan dengan berbagai cara. Diantaranya adalah dengan memilih metode pembelajaran yang tepat. Pemilihan metode pembelajaran oleh pendidik tentunya berpengaruh pada setiap aspek pembelajaran. Sesuai dengan Permen No 44/2015 tentang SN-PT pembelajaran di perguruan tinggi harus lebih terpusat pada siswa atau Student Centered Learning (SCL). Sehingga diperlukan pemilihan metode yang tepat agar dapat mengoptimalkan tingkat kemandirian mahasiswa dalam belajar. Berdasarkan hasil pengamatan yang peneliti lakukan pada mahasiswa semester V PGSD FKIP Unisri di tahun ajaran 2016/2017, diketahui bahwa mahasiswa belum memiliki kemandirian belajar. Hal ini terlihat dari ketidaksiapan mahasiswa dalam melanjutkan materi perkuliahan, karena mahasiswa belum mempelajari materi yang akan dibahas. Bahkan penugasan yang diberikan peneliti untuk membaca dan mempelajari materi tidak dilakukan dengan baik. Sebagian besar mahasiswa tidak mempelajarinya bahkan sebagian lupa dengan tugas tersebut. 
Kemandirian mahasiswa untuk mempelajari materi perkuliahan secara individu sangat penting agar proses belajar berjalan dengan optimal. Ahmadi dan Uhbiyati (dalam Husein, 2013: 12) kemandirian belajar adalah belajar mandiri, tidak menggantungkan diri kepada orang lain, siswa dituntut untuk memiliki keaktifan dan inisiatif sendiri dalam belajar, bersikap, berbangsa, maupun bernegara. Sikap kemandirian belajar ini sangat dibutuhkan oleh setiap peserta didik dalam proses pembelajaran. Sedangkan menurut Brookfield (dalam Husein, 2013: 13) kemandirian belajar merupakan kesadaran diri, digerakkan oleh diri sendiri, kemampuan belajar untuk mencapai tujuannya. Peserta didik yang memiliki sikap kemandirian belajar, maka ia akan merencanakan proses belajarnya sendiri dan mengevaluasi belajarnya.

Pengembangan potensi diri siswa akan berjalan dengan efektif apabila seorang mampu menggunakan model dan media mengajar yang tepat (Sulistyaningrum, 2017: 154). Pengembangan potensi diri berupa kemandirian mahasiswa agar terlatih dan mempunyai kebiasaan melakukan tindakan yang baik serta dapat mengatur setiap tindakannya sehingga mahasiswa mempunyai kedisiplinan dalam proses belajar. Dalam pembelajaran, kemandirian sangat dibutuhkan agar mahasiswa mempunyai tangungjawab dalam mengatur dan mendisiplinkan dirinya, selain itu dalam mengembangkan kemampuan belajar atas kemauan sendiri. Kemandirian ini menekankan pada aktivitas dalam belajar yang penuh tanggungjawab sehingga mampu mencapai hasil belajar yang baik. Kemandirian mahasiswa dapat dilatih menggunakan suatu model pembelajaran yang terencana dan terukur dengan baik, dan dalam penelitian ini akan diberikan model pembelajaran tutor sebaya.

Joyce dan Weil (1980: 2) mendefinisikan model pembelajaran adalah sebagai suatu pola atau strategi yang sudah direncanakan sedemikian rupa dan digunakan untuk menyusun kurikulum, mengatur materi pelajaran dan memberi petunjuk pada guru di dalam kelasnya. Istilah model pembelajaran mencakup suatu pendekatan pembelajaran yang lebih luas dan menyeluruh. Pendapat tersebut sejalan dengan Chen (2010: 6) yang menyatakan bahwa "tutor sebaya merupakan bimbingan, bantuan belajar oleh teman sebaya kepada peserta didik yang kurang dalam pemahaman materi secara sistematis untuk memahami materi. Menurut Kusdiono (Taswadi, 2012: 11) bahwa tutor adalah seorang/beberapa orang peserta didik yang ditunjuk dan ditugaskan untuk membantu peserta didik yang mengalami kesulitan dalam belajar.

Model pembelajaran tutor sebaya dirasakan sangat bermanfaat sebagai alternatif pengganti pembelajaran konvensional dalam kelas besar di mana guru dapat memberikan bantuan secara maksimal kepada peserta didiknya dengan bantuan tutor selama proses pembelajaran berlangsung. Hal ini sejalan dengan pendapat Arjanggi dan Suprihatin (2010: 92) yang menyatakan bahwa "Metode pembelajaran tutor teman sebaya mempunyai kontribusi sebesar 17,4 persen dalam upaya meningkatkan hasil belajar berdasar regulasi diri pada mahasiswa". Selain itu penggunaan model 
pembelajaran tutor sebaya juga dapat meningkatkan keaktifan dan prestasi belajar peserta didik. Hal ini sejalan dengan pendapat Maryani (2010: 23) yang menyatakan bahwa terdapat peningkatan keaktifan dan prestasi belajar akuntansi melalui penerapan metode pembelajaran tutor sebaya.

Penelitian yang dilakukan oleh Lysynchuk, et al, 1992; Palinsar \& Brown, 1984; Rosenshine \& Meiser, 1992; Slavin, 2008; (dalam Wawan, 2012) secara umum menemukan pengaruh positif dari penggunaan metode tutor sebaya. Demikian juga penelitian Supardi, 2009; Laila, 2009; Sobarningsih, 2008; Irawan, 2008; Mulyati, 2007; Suwanda, 2008; Suyuti, 2008 (dalam Wawan, 2012), yang secara umum menyimpulkan bahwa model tutor sebaya dapat meningkatkan pemahaman, penguasaan konsep, kreativitas, komunikasi dan gairah belajar siswa dibanding dengan pembelajaran konvensional.

Azhar (2011: 49) menyatakan bahwa video merupakan gambar-gambar dalam frame, di mana frame demi frame diproyeksikan melalui lensa proyektor secara mekanis sehingga pada layar terlihat gambar hidup. Video merupakan salah satu jenis media audio-visual dan dapat menggambarkan suatu objek yang bergerak bersama-sama dengan suara alamiah atau suara yang sesuai. Video menyajikan informasi, memaparkan proses, menjelaskan konsep, mengajarkan keterampilan, menyingkat atau memperpanjang waktu, dan mempengaruhi sikap.

Youtube adalah situs berbagai video yang paling popular saat ini. Tentu saja video tidak dengan sendirinya menjadi bahan pembelajaran yang siap pakai. Perencanaan yang matang sesuai dengan tujuan pembelajaran dan pengintegrasian video-video yang tersedia di Youtube sebagai sarana pendukung akan mengoptimalkan capaian pembelajaran karena sesuai dengan gaya belajar dan minat generasi digital. Menurut sebuah survey, sekitar 100.000 video ditonton setiap harinya di Youtube. Setiap 24 jam ada 65.000 video baru diunggah ke Youtube. Setiap bulannya Youtube dikunjungi 20 juta penonton dengan mayoritas kisaran usia antara 12-17 tahun (Burke, Snyder, \& Rager, 2009).

Youtube bisa menjadi sumber belajar dan media pembelajaran yang bisa memenuhi tuntutan kebutuhan generasi digital. Youtube bisa meningkatkan minat dan mendukung gaya belajar generasi digital. Youtube juga menawarkan pengalaman pembelajaran dengan teknologi yang baru yang akan berguna saat mereka lulus (Burke, Snyder, \& Rager, 2009). Selain itu Youtube juga menyediakan ratusan ribu video dengan berbagai ragam topic yang bisa diintegrasikan dalam pembelajaran di kelas. Youtube juga akan menjadi perpustakaan video gratis yang sangat luas bagi pembelajar yang akan mendorong mereka menjadi pembelajar yang mandiri.

Terkait berbagai masalah di atas, maka diperlukan adanya penelitian lebih lanjut untuk menguji pengaruh suatu metode pembelajaran terhadap sikap kemandirian belajar mahasiswa. Dalam hal ini peneliti akan menguji pengaruh metode pembelajaran tutor 
sebaya berbasis video Youtube terhadap sikap kemandirian mahasiswa dalam belajar. Metode tutor sebaya berbasis Video Youtube yang dimaksudkan dalam penelitian ini adalah mahasiswa ditugaskan untuk menjadi tutor melalui media internet atau dengan kata lain mahasiswa berperan sebagai tutor yang menjelaskan salah satu materi perkuliahan dalam bentuk video dan selanjutnya diunggah di internet dan mahasiswa yang lain memberikan tanggapan maupun pertanyaan yang terkait materi tersebut.

\section{METODE PENELITIAN}

Penelitian ini berjenis quasi eksperimen menggunakan pretest postes design. Populasi dalam penelitian ini adalah mahasiswa PGSD FKIP UNISRI tahun akademik 2016/2017 yang berjumlah 114 mahasiswa, dan kemudian dilakukan simple random sampling dihasilkan sampel berjumlah 30 mahasiswa. Teknik pengumpulan data yang digunakan adalah angket dan dokumentasi. Teknik analisis data yang digunakan untuk menguji hipotesis adalah mengunakan uji-t dengan taraf signifikansi 5\% yang dilakukan menggunakan aplikasi SPSS versi 21.00. Sedangkan untuk menguji efektivitas tutor sebaya berbasis video Youtube diuji menggunakan uji N-Gain.

\section{HASIL DAN PEMBAHASAN}

Data dalam penelitian ini diperoleh dari mahasiswa Prodi S1 PGSD UNISRI semester II kelas 01 dengan jumlah 30 mahasiswa. Data yang diperoleh meliputi: nilai sikap kemandirian belajar mahasiswa PGSD UNISRI antara sebelum dan sesudah menggunakan pembelajaran dengan metode tutor sebaya berbasis video Youtube. Perbandingan hasil antara sebelum dan sesudah menggunakan pembelajaran dengan metode tutor sebaya berbasis video Youtube, disajikan dalam tabel 1 dan gambar 1 .

Tabel 1. Distribusi Frekuensi Sikap Kemandirian Belajar Mahasiswa Sebelum dan Sesudah Menggunakan Metode Tutor Sebaya Berbasis Video Youtube.

\begin{tabular}{|c|c|c|c|c|c|c|}
\hline \multirow[b]{2}{*}{ interval } & \multicolumn{2}{|c|}{ Sebelum } & \multirow[b]{2}{*}{$\begin{array}{c}\text { Ukuran pemusatan } \\
\text { penyebaran }\end{array}$} & \multicolumn{2}{|c|}{ Sesudah } & \multirow[b]{2}{*}{$\begin{array}{c}\text { Ukuran pemusatan } \\
\text { penyebaran }\end{array}$} \\
\hline & $\mathbf{F i}$ & $\begin{array}{l}\text { Frek. } \\
\text { relatif }\end{array}$ & & $\mathbf{F i}$ & Frek. relatif & \\
\hline $91-120$ & 0 & 00,00 & $\bar{x}=59,9$ & 29 & 97,00 & $\bar{x}=104,03$ \\
\hline $61-90$ & 14 & 47,00 & $\mathrm{Me}=58,5$ & 1 & 3,00 & $\mathrm{Me}=104,5$ \\
\hline $31-60$ & 16 & 53,00 & $\mathrm{Mo}=58$ & 0 & 00,00 & $\mathrm{Mo}=103$ \\
\hline $0-30$ & 0 & 00,00 & $S=5,58$ & 0 & 00,00 & $S=5,70$ \\
\hline Jumlah & 30 & 100,00 & & 30 & 100,00 & \\
\hline
\end{tabular}


Data sikap kemandirian belajar mahasiswa diperoleh dari instrumen yang dibuat berupa angket yang digunakan untuk mengukur sikap kemandirian belajar mahasiswa.

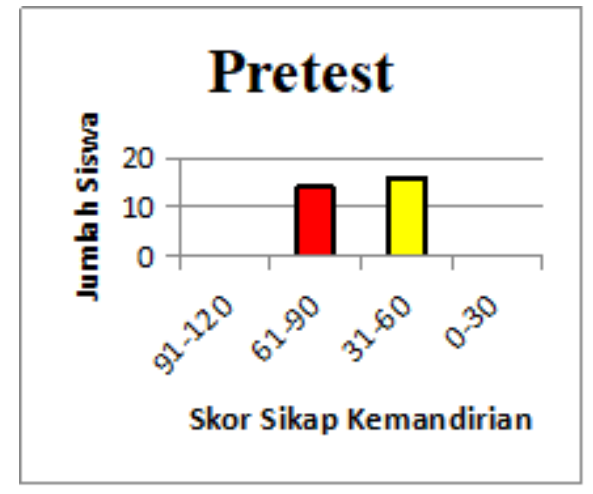

Gambar 1. Grafik Sikap Kemandirian Belajar Mahasiswa Sebelum Menggunakan Pembelajaran Dengan Metode Tutor Sebaya Berbasis Video Youtube

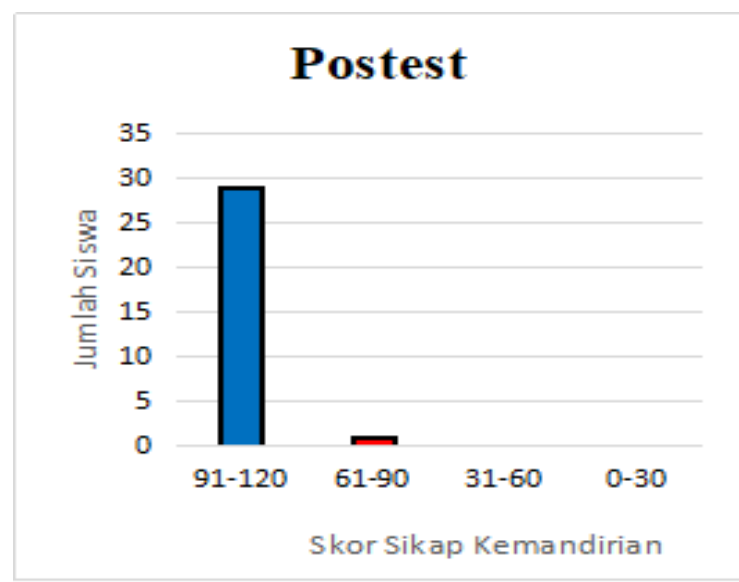

Gambar 2. Grafik Sikap Kemandirian Belajar Mahasiswa Sesudah Menggunakan Pembelajaran Dengan Metode Tutor Sebaya Berbasis Video Youtube

Hipotesis pertama menyatakan "Ada perbedaan sikap kemandirian belajar mahasiswa PGSD UNISRI antara sebelum dan sesudah menggunakan pembelajaran dengan metode tutor sebaya berbasis video Youtube". Untuk mengujinya menggunakan uji Paired Sample T-test dengan bantuan program spss versi 21. Hasil dari uji t berpasangan terlihat bahwa rata-rata perbedaan sikap kemandirian belajar sebelum dan sesudah menggunakan metode tutor sebaya berbasis video Youtube adalah sebesar 49,01. Artinya ada peningkatan sikap kemandirian belajar. Hasil perhitungan nilai " $t$ " adalah sebesar - 49,01 dengan sig (2-tailed) sebesar 0,000 yang nilainya kurang dari 0,05. Hal ini berarti menolak $\mathrm{H}_{0}$ dan dapat disimpulkan bahwa ada perbedaan signifikan sikap kemandirian belajar sebelum dan sesudah menggunakan metode tutor sebaya berbasis video Youtube. 
Hipotesis kedua tentang efektifitas metode tutor sebaya yang dianalisis menggunakan rumus $\mathrm{N}$-gain diperoleh angka sebesar 0,734 yang artinya keefektifan dari penggunaan metode tutor sebaya berbasis video Youtube dalam peningkatan sikap kemandirian belajar pada kriteria tinggi.

Berdasarkan hasil perhitungan di atas diketahui bahwa ada perbedaan signifikan mengenai kemandirian belajar mahasiswa antara sebelum dan sesudah menggunakan metode tutor sebaya berbasis video Youtube. Hasil penelitian ini sejalan dengan penelitian yang dilakukan Fitriani (2013) yang mengkaji tentang peningkatan kemandirian dan hasil belajar matematika bagi siswa SMP Negeri 1 Polanharjo kelas VIIB semester genap tahun ajaran 2012/2013 melalui strategi pembelajaran Metakognitif Berbasis Tutor Sebaya. Penerapan Metode tutor sebaya berbasis video Youtube dalam pembelajaran menjadikan siswa lebih antusias mengikuti pelajaran, lebih terampil dalam mencari sumber belajar serta mengerjakan tugas dan sikap kemandirian belajar siswa meningkat secara signifikan.

Pembelajaran menggunakan Metode tutor sebaya berbasis video Youtube adalah salah satu cara yang dapat memicu sikap kemandirian belajar mahasiswa yang tidak hanya menerima materi dari dosen tetapi berinisiatif dalam pencarian materi-materi perkuliahan, melakukan diskusi ilmiah yang intensif dengan teman dan mempresentasikan hasilnya dalam sebuah video. Hasil pembelajaran dengan nuansa diskusi kelompok dengan teman sebaya memiliki pengaruh yang positif untuk meningkatkan hasil belajar mahasiswa, sebagaimana hasil penelitian Satrianawati (2015: 141-147) yang menguji metode diskusi kelompok menggunakan maindmap berpengaruh signifikan terhadap hasil belajar siswa..

Kondisi sikap kemandirian belajar memang harus dibentuk, adapun yang menjadi faktor yang berpengaruh dalam kemandirian belajar seperti yang disampaikan Syam (dalam Husein, 2013: 19) ada dua faktor yang mempengaruhi kemandirian belajar yaitu: 1) Faktor internal dengan indikator tumbuhnya kemandirian belajar yang terpancar, yang meliputi sikap bertanggung jawab untuk melaksanakan apa yang dipercayakan dan ditugaskan, kesadaran hak dan kewajiban siswa disiplin moral yaitu budi pekerti yang menjadi tingkah laku, kedewasaan diri mulai konsep diri, motivasi sampai berkembangnya pikiran, karsa, cipta, karya, kesadaran mengembangkan kesehatan rohani dan kekuatan jasmani dan disiplin diri dengan mematuhi tata tertib yang berlaku, sadar hak dan kewajiban. 2) Faktor eksternal sebagai pendorong kedewasaan dan kemandirian belajar yang meliputi potensi jasmani rohani yaitu tubuh yang sehat dan kuat dan lingkungan hidup dan sumber daya alam.

Keefektifan penggunaan metode tutor sebaya berbasis video Youtube dalam peningkatan kemandirian belajar masuk dalam kriteria tinggi. Hal ini dikarenakan dalam pembelajaran menggunakan metode tutor sebaya berbasis video Youtube 
menjadikan mahasiswa melakukan beberapa tahapan kegiatan yang dapt mengaktifkan dan membuat mereka mandiri. Tahapan kegiatan itu adalah:

1. Mahasiswa harus mengetahui materi yang menjadi tugasnya

2. Mahasiswa harus mencari sumber belajar sendiri materi menjadi tugasnya

3. Mahasiswa harus berusaha memahami materi yang menjadi tugasnya.

4. Mahasiswa harus mempresentasikan materi tersebut tetapi dalam wujud video. Dalam pembuatan video tersebut tentunya perlu persiapan dan pelaksanaan yang matang.

5. Mahasiswa harus menanggapi pertanyaan dari teman-temannya terkait dengan materi yang menjadi tugasnya

Dari banyaknya tahapan yang harus dilakukan mahasiswa tersebut sehingga menjadikan mahasiswa lebih mandiri. Dalam hal ini dosen hanya sebagai fasilitator yang fungsi utamanya menjamin kegiatan mahasiswa berjalan, memperbaiki kesalahan siswa dalam presentasinya, menambahkan jika presentasinya kurang lengkap, mengatur arus tanya jawab, dan mengevaluasi kegiatan mahasiswa.

\section{SIMPULAN}

Berdasarkan hasil penelitian yang telah dilakukan, maka dapat diambil kesimpulan sebagai berikut :

1. Ada perbedaan sikap kemandirian belajar mahasiswa PGSD UNISRI antara sebelum dan sesudah menggunakan pembelajaran dengan Metode tutor sebaya berbasis video Youtube. Dari hasil uji t didapat sig (2-tailed) sebesar 0,000 yang nilainya kurang dari 0,05 . Hal ini berarti menolak $\mathrm{H}_{0}$ dan dapat disimpulkan bahwa ada perbedaan signifikan sikap kemandirian belajar sebelum dan sesudah menggunakan Metode tutor sebaya berbasis video Youtube.

2. Pembelajaran menggunakan Metode tutor sebaya berbasis video Youtube efektif dalam meningkatkan sikap kemandirian belajar mahasiswa PGSD UNISRI. Hasil perhitungan dengan $\mathrm{N}$-gain yaitu sebesar 0,734 yang artinya keefektifan dari penggunaan metode tutor sebaya berbasis video Youtube dalam peningkatan sikap kemandirian belajar pada kriteria tinggi.

\section{DAFTAR PUSTAKA}

Ali Mohammad dan Mohammad Asrori. 2012. Psikologi Remaja: Perkembangan Peserta Didik. Jakarta: PT Bumi Aksara.

Anderson Ronald. (1987). Pemilihan dan Pengembangan Media Untuk Pembelajaran. Jakarta: Rajawali Press. 
Andi Prastowo. (2012). Panduan Kreatif Membuat Bahan Ajar Inovatif. Yogyakarta: Diva Press

Arjanggi, R. \& Suprihatin, T. (2010). "Metode Pembelajaran Tutor Teman Sebaya Meningkatkan Hasil Belajar Berdasar Regulasi Diri”. Jurnal Makara, Sosial Humaniora, Vol. 14, No. 2, hlm. 91 - 97. http://hubsasia.ui.ac.id/old/index.php/ hubsasia/article/view/666

Arsyad, Azhar (2011). Media Pembelajaran. Bandung: Rajawali Press

Barnes, K., R. Marateo, and S. Ferris. 2007. Teaching and learning with the net generation. Innovate 3 (4). Diakses pada 15 mei 2017 dari situs http://www.innovateonline.info/index.php?view=article \&id=382 .

Basuki Wibawa dan Farida Mukti. (1991). Media Pengajaran. Jakarta: Depdikbud.

Burke, S.C., Snyder, S., Rager, R.C. 2009. An Assessment of Faculty Usage of YouTube as a Teaching Resource. The Internet Journal of Allied Health Sciences and Practice. Vol. 7 No. 1. http://ijahsp.nova.edu

Chen, C. \& Liu, C.C. (2010). "A Case Study of Peer Tutoring Program in Higher Education". Research in Higher Education Journal.

Clarkson, B. \& Luca, J. (2002). "Promoting Student Learning Through Peer Tutoring A Case Study". Proceedings of World Conference on Educational Multimedia, Hypermedia and Telecommunications. In P. Barker \& S. Rebelsky (Eds.).

Daryanto. (2011). Media Pembelajaran. Bandung: PT. Sarana Tutorial Nurani Sejahtera.

Desmita. 2010. Psikologi Perkembangan Peserta Didik. Bandung: PT Remaja Rosdakarya.

Fitriani. Asri 2013. "Peningkatan Kemandirian Dan Hasil Belajar Matematika Melalui Strategi Metakognitif Berbasis Tutor Sebaya Bagi Siswa SMP”. Artikel Publikasi Program Studi Pendidikan Matematika, Universitas Muhammadiyah Surakarta. http://eprints.ums.ac.id/23452/

Husein, Ahmad. 2013. "Implementasi Model Pembelajaran Kooperatif Berbasis Lingkungan untuk Meningkatkan Kemandirian Belajar dan Hasil Belajar Siswa (Studi pada Mata Pelajaran PKn di SD Negeri Kecamatan Lunang Silaut Kabupaten Pesisir Selatan”.Tesis. Bengkulu. Program Studi Pascasarjana (S2) Tekhnologi Pendidikan FKIP Universitas Bengkulu. 
Joyce, Bruce and Weil, Marsha. 1980. Models of Teaching (Second Edition). Englewood Cliffs, New Jersey: Prentice-Hall, Inc.

Kemendiknas. 2010. Pengembangan Pendidikan Budaya dan Karakter Bangsa. Jakarta: Kementrian Pendidikan Nasional Badan Penelitian dan Pengembangan Pusat Kurikulum.

Maryani. (2010). Penerapan Metode Pembelajaran Tutor Sebaya Untuk Meningkatkan Prestasi Belajar Akuntansi pada Siswa Kelas X AK 1 SMK Batik 2 Surakarta. Skripsi pada Fakultas Keguruan dan Ilmu Pendidikan. Universitas Sebelas Maret Surakarta: tidak diterbitkan.

Miranti Kuku. 2011. Peningkatan Kemampuan Menyimak Cerita Anak Menggunakan Media Video Siswa Kelas IV SD N Kotagede V Yogyakarta. Yogyakarta: UNY

Satrianawati. 2015. "Pengaruh Metode Diskusi kelompok Dalam Evaluasi Hasil Belajar Mahasiswa Menggunakan Mindmap”. Jurnal Profesi Pendidikan Dasar, Vol. 2, No. 2, Desember, hlm. 141-147. http://journals.ums.ac.id/ index.php/ppd/article/view/1649

Setiawan, Y., Akhdinirwanto, R.W., \& Maftuhkhin, A. (2013). "Peningkatan Kemandirian Belajar Melalui Tutor Sebaya Pada Siswa MAN Purworejo Tahun Pelajaran 2011/2012”. Jurnal Radiasi, Vol. 1, No. 1, http://ejournal.umpwr.ac.id/ index.php/radiasi/article/view/308

Sugiyono. 2010. Metode Penelitian Pendidikan: Pendekatan Kuantitatif, Kualitatif, dan $R \& D$. Bandung: Alfabeta. Sukardi. 2010. Metodologi Penelitian Pendidikan. Jakarta:Bumi Aksara

Sukmadinata. 2008. Metode Penelitian Pendidikan. Bandung: PT Remaja Rosdakarya.

Sulistyaningrum, Dewi Ayu. 2017. "Pengembangan Quantum Teaching Berbasis Video Pembelajaran Camtasia Pada Materi Permukaan Bumi dan Cuaca". Jurnal Profesi Pendidikan Dasar, Vol. 4, No. 2, Desember, hlm 154-166. http://journals.ums.ac.id/index.php/ppd/article/view/5067.

Taswadi. (2012). Metode Pembelajaran Tutorial Teman Sebaya untuk Meningkatkan Keterampilan Menggunakan Komputer dalam Mata Kuliah Komputer dan Media Pembelajaran. Sekolah Pasca Sarjana UPI Bandung: tidak diterbitkan untuk umum. 